\title{
Discourses on Learning in Education: Making Sense of a Landscape of Difference
}

\author{
Brent Davis ${ }^{* \dagger}$ and Krista Francis ${ }^{\dagger}$ \\ Werklund School of Education, University of Calgary, Calgary, AB, Canada
}

There are hundreds, perhaps thousands, of "theories of learning" at play in the field of education. Given scant agreements on the meaning of "learning" and the purpose of "theory," such quantity is perhaps unsurprising. Arguably, however, this situation is indefensible and debilitating in an academic domain so focused on interpreting and influencing learning. We describe our own efforts to come to terms with this matter. Oriented by Conceptual Metaphor Theory and network theory, we are attempting to "map" contemporary treatments of learning-whether implicit or explicit, written or spoken, descriptive or prescriptive, formal or informal, scientific or folk. We report on our iterative process, evolving design, and emergent insights. We discuss the potential relevance of this and similar efforts for the future of educational research and practice.

Edited by:

Cheryl J. Craig,

Texas A\&M University, United States

Reviewed by:

Yu Hua Bu,

East China Normal University, China Jesper Haglund,

Karlstad University, Sweden

*Correspondence:

Brent Davis

brent.davis@ucalgary.ca

tThese authors have contributed equally to this work.

Specialty section: This article was submitted to

Teacher Education,

a section of the journal

Frontiers in Education

Received: 31 August 2021 Accepted: 04 November 2021

Published: 08 December 2021

Citation:

Davis B and Francis K (2021)

Discourses on Learning in Education: Making Sense of a Landscape of Difference.

Front. Educ. 6:760867. doi: $10.3389 /$ feduc.2021.760867
Keywords: learning, cognition, learning theory, epistemology, educational theory

\section{INTRODUCTION}

Some years ago, we attended a series of symposia offered by shortlisted applicants for academic positions, in which candidates were asked to speak to the "theory of learning that most oriented [their] research and teaching." Listed alphabetically, they presented on Cognitive Science, Critical Realism, Cultural-Historical Psychology, Feminist Pedagogy, Grit, and Ubiquitous Learning.

After listening, we wondered if any of the speakers had actually addressed a "theory of learning." In their presentations, Cognitive Science and Cultural-Historical Psychology were characterized as domains of inquiry, Feminist Pedagogy and Ubiquitous Learning were presented in terms of teaching, and the treatments of Grit and Critical Realism did not seem to touch on what learning is or how it happens. We found ourselves worried not just that the request to speak to learning theories had been misinterpreted, but that there may be scant agreement among educational researchers on what "theory" means and what a "theory of learning" should do.

A Google search of "learning theories" amplified such concerns. Each of the first 20 results in a search conducted today (2021 August 12) can be unambiguously categorized as either:

- a reduction-of the sort, "There are $n$ (types of) learning theories," where $n$ ranged from 3 to 6 , most commonly: Behaviorism, Cognitivism, Constructivism, and Socio-Cultural Theory; or

- an annotated list-of the variety, "There are $x$ learning theories," where $x$ ranged from 15 to 108.

${ }^{1}$ Note on style: This writing reports on a survey and evolving database of discourses on learning. A capitalized name indicates that the discourse is included in the database. 
All of the sites we viewed were explicitly developed by and/or for practicing educators. It was thus troubling that most projected senses of comprehensiveness through titles such as "The Five Educational Learning Theories," "Learning Theories: Understanding the four Major Ones for the Classroom," and "15 Learning Theories in Education (A Complete Summary)." While several sites offered somewhat detailed summaries of individual theories, none addressed underlying assumptions, presented empirical support, or offered critical comparisons to other perspectives.

Much the same can be said of the print literature aimed at academics. There are dozens of "handbooks" and "encyclopedias" of learning, but most are focused on specific domains (e.g., mathematics education) and/or subsets of discourses (e.g., Socio-Cultural Theories figure prominently in recent publications). Indeed, we were able to locate only one recent publication that attempted a comprehensive review of historical and contemporary perspectives on learning, namely the monolithic Encyclopedia of the Sciences of Learning (Seel, 2012). Yet, while impressively broad in scope, it comprises discrete explications contributed by many authors, and so there is very limited comparison of perspectives and no consistent examination of assumptions.

Provoked by such experiences, for the past several years we have been working on a comparative survey of interpretations of learning that are represented in professional and academic literatures. This work was oriented by the suspicion that, across the hundreds of self-described "theories of learning" at play in the field of education, there is scant agreement on the meaning of "learning." Indeed, as we develop, it is not always clear that varied uses of the word "learning" are in fact in reference to the same general phenomenon.

To be clear, we do not mean to call for a unified definition or to imply that "learning" can be applied to only one phenomenon. On the contrary, as developed below, we believe there is great value in diversities of interpretation and application. However, we also believe that such value is likely to go unrealized if divergences in focus are not signaled, if implicit meanings are allowed to operate without being interrogated, and if specific discourses are permitted to operate in silos. Our ongoing efforts to develop a comparative survey of interpretations of learning are thus oriented by the hope that a broad analysis of usages of "learning" might enable educational efforts-a hope that is motivated by research in the cognitive sciences, discussed below, that suggests descriptions of a phenomenon can summon prescriptions for acting relative to that phenomenon.

In this work, we attend to academic, professional, and popular treatments, oriented by the realization that many influential perspectives-such as Constructivism, Constructionism, and Socio-Cultural Theory-are often represented in very different ways across the literatures intended for university-based researchers, school-based teachers, and the broader public. In fact, often some highly influential interpretations of these theories among practicing teachers bear scant resemblances to versions developed and investigated in the academic world (Davis and Sumara, 2003a, Davis and Sumara, 2003b). Thus, while the center of this work is scholarship in the field of education, the scope of consideration is necessarily broader.

Given the vibrancy of discussions, the variety of perspectives, the ranges of interpretation and application, the contested character of the notion of "theory," and the tacit nature of many perspectives, it is clear that a complete inventory is not achievable. Instead, we have been working on a flexible, evolving website database of "Discourses on Learning in Education." 2 The shift in phrasing from "theories" to "discourses," evident in this title, was an almost immediate decision in this project, and it parallels the move to include professional and popular sources, mentioned in the previous paragraph. The word "theory" is not well fitted to our purposes because, as is immediately evident in the contrast between notions of "scientific theory" and "folk theory," scholarly and popular meanings can be incompatible. Indeed, it was obvious as we juxtaposed an initial cluster of a few dozen perspectives that there were dramatic differences in conceptions of and commitments to scientific rigor just among academic publications. As we discuss, some of the most prominent and influential "learning theories" appear to have virtually no empirical support, while some perspectives on human learning backed by extensive and verified evidence appear to be all but ignored in the popular educational literature.

We thus opted for the word "discourse"-which, according to most dictionary definitions, is sufficiently flexible to reach across scientific perspectives, broad philosophies, everyday wisdom, research domains, personal opinions, professional practices, and descriptive models. We acknowledge that this popular meaning departs from narrower usages of some academic Discourse Theories, particularly those that are centrally concerned with matters of establishing and maintaining power structures, legitimizing specific interpretations of truth and reality, and the creation, maintenance, and negotiation of individual identities and social positionings (Macdonell, 1986). That said, these foci of Discourse Theories are certainly consistent with the intentions of our work, in addition to being central concerns of many of the discourses surveyed.

Our growing database includes analyses of over 2000 discourses. Our hope in this project is that it might support efforts in the field to become more critically aware of the assumptions and assertions about learning that infuse academic inquiry and professional action. A purpose in this writing is to speak to some of the insights gleaned through this project of surveying, summarizing, contrasting, and clustering discourses on learning in education. These insights are distributed across the sections. Each phase of the project has presented its own challenges and has sponsored its own realizations on how matters of learning are addressed within the field of education.

In the first section, we describe the orienting phase of the work, laying out major theoretical, interpretive, and procedural decisions. In the second section, we discuss some of the "meta" decisions and accompanying insights that arose while

${ }^{2}$ The URL is https://learningdiscourses.com. We write from the assumption that readers have access to the website. 
grappling in the second phase with strategies to represent varieties of meaning, assertion, and assumption. In the third section, we speak to emergent realizations associated with ongoing efforts to expand the database. Finally, we reflect on implications of this work for educational research and practice.

\section{PHASE 1: THE INITIAL DATABASE}

\section{Theoretical Commitments}

We began our careers in educational research, respectively, in the early 1990s within mathematics education and the early 2000s through educational technology. Davis's education on matters of knowledge and learning was framed by an interest in Embodied Cognition and against a backdrop of vibrant debate among proponents of Radical Constructivism and advocates of SocioCultural Theory (see, e.g., Cobb, 1994). A decade later, Francis's most significant influences included Social Constructivism, Knowledge Building, and Complex Systems Research.

Common to these influences is the suggestion that truths and claims to knowledge might be construed as dynamic coherences-that is, claims to truth are elements of everevolving ecosystems of thought that contribute to and rely on larger, vibrant systems and situations. Accordingly, across the influences mentioned in the preceding paragraph, learning is understood as an iterative, participatory process of generating and enacting knowledge. These commitments have been integral to our analyses and models. That detail matters. Differently oriented researchers would have arrived at very different strategies of organization and representation-as illustrated by the websites mentioned earlier.

To the issue of different orientations, ours is informed by Conceptual Metaphor Theory (Lakoff and Johnson, 1999; Fauconnier and Turner, 2003), which recognizes metaphor as a primary mode of human thought. Specifically, the theory examines how metaphor makes it possible to understand one conceptual domain in terms of another-in the process, orienting perception, interlinking interpretations, and prompting action.

As we discuss in more detail below, a tenet of Conceptual Metaphor Theory is that metaphors never stand alone. It is important to consider their ecosystems of association and their webs of consequence. As Kelly (2010) signaled, "They come woven in a web of auxiliary ideas, consequential notions, supporting concepts, foundational assumptions, side effects, and logical consequences and a cascade of subsequent possibilities. Ideas fly in flocks. To hold one idea in mind means to hold a cloud of them" (pp. 44-45).

Cognitive scientists Thibodeau and Boroditsky (2013, 2015) made the point in more technical terms. In their studies of how natural language metaphors affect humans reasoning, they have provided empirical evidence of another tenet of Conceptual Metaphor Theory, namely that metaphors play distinct and observable, but often covert, roles in reasoning by channeling attentions to particular paths of inference and plans of action. Concisely, descriptions summon prescriptions. Shifts as subtle as changing a single noun can trigger major rethinkings and changes to action-an observation that Thibodeau and Boroditsky (2015) used to underscore that a metaphor "does not act alone. ... [It] instantiates a knowledge frame that then can coerce other information ... into the frame" (p. 14).

There are many instances of such coercion of thought-that is, of self-referencing and consequential flocks of association-across contemporary discourses on learning. For instance, as Sfard (1998) elaborated, LEARNING AS ACQUISITION ${ }^{3}$ buttresses and is braced by such inextricably entangled notions as KNOWLEDGE AS OBJECT, LEARNER AS RECEPTABLE, INTELLIGENCE AS CAPACITY, and TEACHING AS DELIVERING.

Our attentiveness to metaphor has proven especially useful in efforts to highlight convergences and divergences among diverse perspectives on learning, for a perhaps-surprising reason: While there are literally thousands of active discourses on learning in education, there appear to be only a few dozen distinct flocks of metaphors in play. Conceptual Metaphor Theory, that is, not only provides a means to study convergences and divergences of discourses on learning; it affords an effective means to grapple with a wildly discursive realm.

\section{Determining Criteria for Inclusion in Our Database}

We began this project with the conviction that any discourse that has been characterized as a "theory of learning" should be included in our database. Unfortunately, that principle proved problematical, for multiple reasons.

Firstly, many discourses that are identified as theories of learning are principally concerned with teaching. Our initial impulse was to ignore such discourses, but we thought otherwise when we realized just how frequently the phrase "theory of learning" is conflated with "theory of teaching"-and that, in fact, very few discourses on learning ignore matters of teaching. We thus opted to include them all, reframing our thinking in terms of a continuum, with interpreting learning (i.e., what it is, associated psychological, social, cultural, and ecological dynamics, etc.) at one end and influencing learning (i.e., causing/triggering it, defining what should be learned, measuring it, etc.) at the other.

A second problem arose in the fact that "theories" of learning are not always explicitly identified as such. Indeed, as Sfard (1998) illustrated with the example of LEARNING AS ACQUISITION, the most pervasive and influential conceptions of learning are likely implicit. Thus, alongside formal discourses, we found it necessary to consider Folk Theories and metaphors that infuse everyday habits of speaking.

A third problem appeared in widespread tendencies to use "theory of learning" to refer to phenomena that are not theories and are not principally about learning, such as broad epistemological frames (e.g., Humanism), educational movements (e.g., Progressivism), professional domains (e.g.,

\footnotetext{
${ }^{3}$ Note on style: Borrowing from Cognitive Science and Conceptual Metaphor Theory, we employ the convention of using SMALL CAPS to set apart specific metaphors.
} 
Psychotherapy), and fields of research (e.g., Cognitive Science). We felt it necessary to include these as well-not because we see such misnomers and reductions as defensible, but because they are common.

That decision prompted our awareness to other discourses that had initially seemed irrelevant. Over recent decades, the word "learning" has been taken up in domains unconcerned with schooling-to describe, for example, transformations of organizations (e.g., Organizational Learning), ecosystems (e.g., Gaia Hypothesis), non-animates (e.g., Plant Learning), and digital technologies (e.g., Cognitive Robotics). While not initially intended to inform formal education, these discourses and their parent domains are clearly contributing to understandings of human learning-in part, as discussed below, by expanding the pool of metaphors to make sense of the phenomenon in ways that may become useful within education. And so, they too were included.

As our pool of discourses grew larger and larger, we did manage to specify a few criteria for exclusion. Firstly, we omitted discipline-specific discourses, such as those focused only on reading or mathematics. This decision was based purely on pragmatics: Taking on discipline-specific discourses would entail a significant enlargement of the pool of discourses, and we simply lack the resources to deal with hundreds or thousands of additional perspectives. That detail is compounded by the fact that our expertise is in STEM domains, and we do not feel competent to represent discipline-specific issues around and interpretations of learning beyond our home domains. Importantly, the decision to omit discipline-specific discourses should not be interpreted as an assumption that the content to be learned is not relevant in discussions of learning. On the contrary, our research outside this project is focused precisely on discipline-specific learning considerations (e.g, Math Minds, 2020).

Secondly, we set a threshold of five references in recognized publications, excluding self-citations. "Recognized publications" here include books, articles in peer-refereed journals, and presentations at major conferences. The count of five mentions is arbitrary, but informative, especially when considered against the fact that some discourses have been cited hundreds of thousands of times. That said, we made no attempt to track or contrast citation statistics, as we did not want to conflate "popular" with "defensible."

With these guidelines in place, we proceeded to consult colleagues, conduct internet searches, mine conference programs, scour library catalogs, and trace references in articles. These activities continue; our "to-do" list perpetually comprises dozens of entries.

\section{Methodological Decisions}

Our next step was to decide on the foci of summaries. That work was oriented by an observation from Sfard (2015): "Whereas everybody seems to agree that learning must be defined as some kind of change, there is no consensus with regard to what it is that changes" (p. 129).

Indeed, regarding "what it is that changes," the span of opinion is broad. Learning is sometimes interpreted as location-specific modifications-of, for example, inner representations (Mentalisms), conditioned responses (Behaviorisms), neuronal interconnectivity (Neuro-Focused Discourses), social practices (Socio-Cultural-Focused Discourses), subjectivity (Identity Discourses), and knowledge systems (Collectivist Learning Theories). Conversely, some accounts frame learning in much more expansive terms, such as trans-systemic evolutions (e.g., Ecological Discourses; Emergent Complexity Discourses).

Attending to what it is that changes was thus a useful starting place for both identifying grounding metaphors and structuring summaries. Specifically, this emphasis led to the decision to foreground the following details in each entry in our database:

- Focus - In under 10 words, we attempted to identify what is seen as changing - and, consequently, to point to the level of analysis of the discourse;

- Principal Metaphors-Appreciating that "ideas fly in flocks," we listed metaphors for knowledge, knowing, learner, learning, and teaching that are associated with "what it is that changes."

Those upfront details frame the following elements:

- Synopsis-a concise description, aimed at under 50 words;

- Commentary - a concise survey of concerns and criticisms.

The brevity of these sections is critical for understanding the project, which we conceive as more analytical than expository. By way of analogy, it is more like a dictionary than an encyclopedia.

As part of our efforts to discriminate among discourses, we also classified each entry in the following ways:

- Status as a Theory of Learning and/or Teaching-We locate each discourse on a continuum, according to how relative emphases on "interpreting learning" and "influencing learning." Rationales are provided.

- Status as a Scientific Theory-We provide brief assessments of each discourse's scientific status, indexed to an operational definition of "scientific" that includes four criteria: a supporting body of evidence; explicit indications of assumptions and metaphors; openness to revision or rejection; and, preferably, consistency with related scientific discourses.

Finally, each entry includes the following elements, based on initial publication dates (where applicable):

- Decade of Emergence

- Authors and/or Prominent Influences

Our summaries, commentaries, assessments, and map placements are based on the writings we have been able to access and informed by the experts we have been able to consult. That said, we openly acknowledge that it is impossible to be thorough in our reviews of available materials. On these matters, we routinely seek out advice and feedback from colleagues and practitioners. More generally, we welcome 
advice and direction from any interested party, especially if it relates directly to postings. Information in entries and locations on the map are routinely updated as colleagues, students, and teachers provide critical feedback.

Perhaps as important as what is included is what we elected to leave out-most obviously, lists of citations. Our main reason for that omission is, as noted above, we envision the project more as a dictionary than an encyclopedia. In projects that are concerned with spectrums of interpretation, multiple meanings, and ranges of application, at some point lists of references become both unruly and uninformative. That is especially the case when discourses are evolving and sources reach beyond academic publications to include classroom resources, blogs, political speeches, websites, and a host of other popular outlets. In such circumstances, web searches are almost certainly superior to reference lists. They are more immediate, more comprehensive, and have greater currency. Searches are also better aligned with the central purpose of our project, to support more critical engagements with discourses on learning in education. We would prefer users to check on and explore beyond our summaries over having them scan extensive lists of sources.

That is not to say that the work is not subject to critical review. On the contrary, across all topics, as noted above, we routinely consult academic and professional authorities. It is standard procedure to check our interpretations with colleagues who have relevant expertise. Scholars from around the world have also provided advice that we have not directly solicited. Additionally, to date, we have used the site as a resource in ten graduate courses and eight undergraduate courses, with a total of well over 1,000 students. Throughout, we have presented our summaries as fallible while signalling our desire for critical feedback. Corrections and elaborations are regularly proposed and routinely incorporated.

\section{PHASE 2: DEVELOPING STRATEGIES TO COMPARE, CONTRAST, AND CONNECT}

\section{A Spatial Interface}

From the start, we conceived of our work in terms of a "map"-a metaphor that we found enabling in its potential for highlighting defining principles and associations with other discourses, which are represented on our map as locations and proximities. The constraints of a map were also useful. Limited to two spatial dimensions, we were forced to weigh carefully our major discriminations.

We were also committed to an online format, partly for features such as searchability and hyperlinking, but mainly for reasons of malleability of content and open access. On the former, a webpage made it possible to add, delete, correct, re-arrange, and reformat as we invented and tested strategies for organization. That is, our webpage serves as much as a medium of experimentation as a means of representation. As for connectivity, a web-based platform has made it possible to involve many others in the thinking and development while making the content broadly available.

\section{Horizontal Axis: Correspondence Discourses vs Coherence Discourses}

The most obvious and immediate consequence of going with a map-like interface is the need to define axes. Based on some previous work (Davis, 2004, 2018), we anticipated that the bifurcation of "Correspondence Discourses" and "Coherence Discourses" would be useful. The expectation was borne out as we analyzed our initial database of summaries, so much so that we elected to use the pairing as the principal axis on the map. That dyad, along with a secondary level of distinctions (and illustrative metaphors for each category), is presented in Figure 1.

A Correspondence Discourse is an epistemological stance that assumes a radical separation of mental (or internal, or mind-based) and physical (or external, or body-based). That separation sets up the need for a correspondence between what is happening outside the knower in the real, objective world and what is happening within the knower's inner, subjective world. Most Correspondence Discourses are developed around овјест-based metaphors (e.g., knowledge seen as a THING, a COMMODITY, BITS OF INFORMATION, a FLUID, a GOAL, and/or a PRODUCT/OUTCOME). Typically, Correspondence Discourses employ line- and arrow-based imagery, rigid binaries/dichotomies/dualisms, and cause-effect Newtonian mechanics. Many Correspondence Discourses are developed around and focused on taxonomies and concern themselves with separating and classifying.

The Correspondence Discourses portion of our horizontal axis is further subdivided into "Mentalisms" and "Behaviorisms." Mentalisms encompass perspectives that frame learning in terms of mental images, models, encodings, or other inner representations of the existing world. Some sort of barrier is posited within most Mentalisms, and it is typically some manner of fallibility associated with the body, such as untrustworthy sensory systems or wired-in biases. Usually, such constraints are seen to render direct, first-hand knowledge of reality impossible.

Behaviorisms share many of the same grounding assumptions, especially around the conviction that learning involves assembling an internal model that maps somehow on external reality. For Behaviorisms, these correspondences are defined operationally, as established and stable repertoires of behavior that are triggered by events in the world. As well, seeking to establish a scientific basis for their claims, behaviorists have rejected attempts to explain learning in terms of unobservable mental processes, opting instead to deal only with phenomena that can be observed and measured. Originally oriented by an analogy of using cables to make connections on a telephone switchboard, learning was imagined in terms of establishing a network of causal relations between stimuli and responses. That network is seen as conditioned by and reflective of (i.e., corresponding to) the real world, but not necessarily representative of it.

The other major category on our horizontal axis is Coherence Discourses, which shift away from THING-based metaphors and 

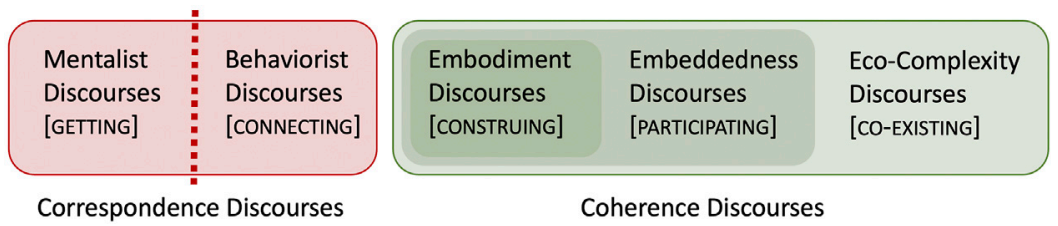

FIGURE 1 | The major categories on the horizontal axis (with illustrative metaphors of learning).

frame matters of knowledge and learning in terms such as AGENCY, PARTICIPATION, and/or BECOMING. Most Coherence Discourses employ biological and ecological metaphors, with dynamics framed in evolutionary terms and relationships framed as COUPLINGS, CO-EVOLUTIONS, and NESTINGS. A secondary cluster of metaphors among Coherence Discourses revolves around CONVERSATIONS, NEGOTIATIONS, CONTRACTS, and ACCORDS.

Among these discourses, the phenomena of knowing, doing, and being are typically engaged as simultaneous and inseparable. That is, a common feature of Coherence Discourses is the rejection of essentialist dyads such as true/false, object/subject, active/passive, individual/collective, and human/ nonhuman-which are generally reframed as dynamic, cospecifying, and aspects that contribute to and rely on larger wholes. Thus, for example, truth is not imagined to be "out there," existing independently of a knower or outside a system of knowing. Rather, a statement is true to the extent that it meshes with a system of interpretation-a notion that, critically, is a commentary on humans' understanding of reality, not a commentary on reality.

The Coherence Discourses portion of our horizontal axis is organized into three nested regions: Embodiment Discourses, Embeddedness Discourses, and Eco-Complexity Discourses. Embodiment Discourses serves as an umbrella notion that is intended to reach across perspectives centrally developed around a rejection of internal/external (mind/body; mental/physical) dichotomies. Among Embodiment Discourses, mental and physical are understood as integrated and inseparable aspects of the body. Phrased differently, the body is not seen as something that a learner learns through, but as the learner. In suit, behaviors are not seen as goals or indications of learning, but as integral to learning.

Embeddedness Discourses span perspectives that refuse separations of self from other and individual from collective. Perceived boundaries among persons and peoples are understood as perceptual necessities rather than absolutes, as collective phenomena are recognized to unfold from and to be enfolded in individual phenomena. That is, social and cultural groups are understood not as collections of learners but as collective learners.

Finally, Eco-Complexity Discourses comprise perspectives on learning that refuse separations of human from nature, material from transcendent, and part from whole. Across most EcoComplexity Discourses, the dynamics of learning are explicitly aligned with the dynamics of evolution-and, indeed, learning and evolution are treated synonymously in some instances.

\section{Vertical Axis: Interpreting Learning vs Influencing Learning}

A significant proportion, and perhaps the majority, of selfidentified "theories of learning" are properly understood as discourses on teaching. In fact, there is a surprisingly even distribution across prominent discourses between those that are principally concerned with the dynamics of learning and those that are mainly focused on the pragmatics of teaching. We used this close-to-even split to define our vertical axis as a continuum. One pole of that continuum is "Discourses on Interpreting Learning," and it is intended to signal those discourses concerned mainly with examining, characterizing, and explaining the dynamics of learning. The other pole is "Discourses on Influencing Learning," where we locate perspectives with greater emphasis on the pragmatic consequences of specific models, metaphors, or principles of learning. To re-emphasize, this Interpreting/Influencing dyad is understood as a continuum rather than a distinction. Few discourses can be unambiguously categorized as concerned strictly with one or the other.

Ten zones are generated when the two subregions of the vertical axis are crossed with the five subregions that define our horizontal axis, as illustrated in Figure 2. In our analysis, most discourses can be unambiguously associated with a single subregion. Some, however, can fit in multiple locations. For clarity, a discourse-specific map that indicates the relevant subregion(s) is included at the bottom of each entry.

There are also some hard-to-place discourses that are articulated in ways that can be embraced across sensibilities. Examples include Learning Transfer, Mastery Learning, and Learning-by-Doing-none of which commit to specific principles of learning or models of teaching. Others in this cluster, such as Deep vs. Surface Learning (Marton and Säljö, 1976), sit across regions by virtue of their explicit contrasts of correspondence-oriented and coherence-oriented sensibilities. These we gathered in a cluster labeled "Unaffiliated Discourses," acknowledging that the strategy of flagging multiple zones for them is not especially informative.

\section{Clusters}

Our horizontal and vertical axes are focused on making discernments, which is why they were purposely selected-that is, they afford means to distribute entries on our map interface. But we are also interested in representing relationships among and similarities across perspectives, such as confluences of concerns, common metaphors, and convergences in meaning. 


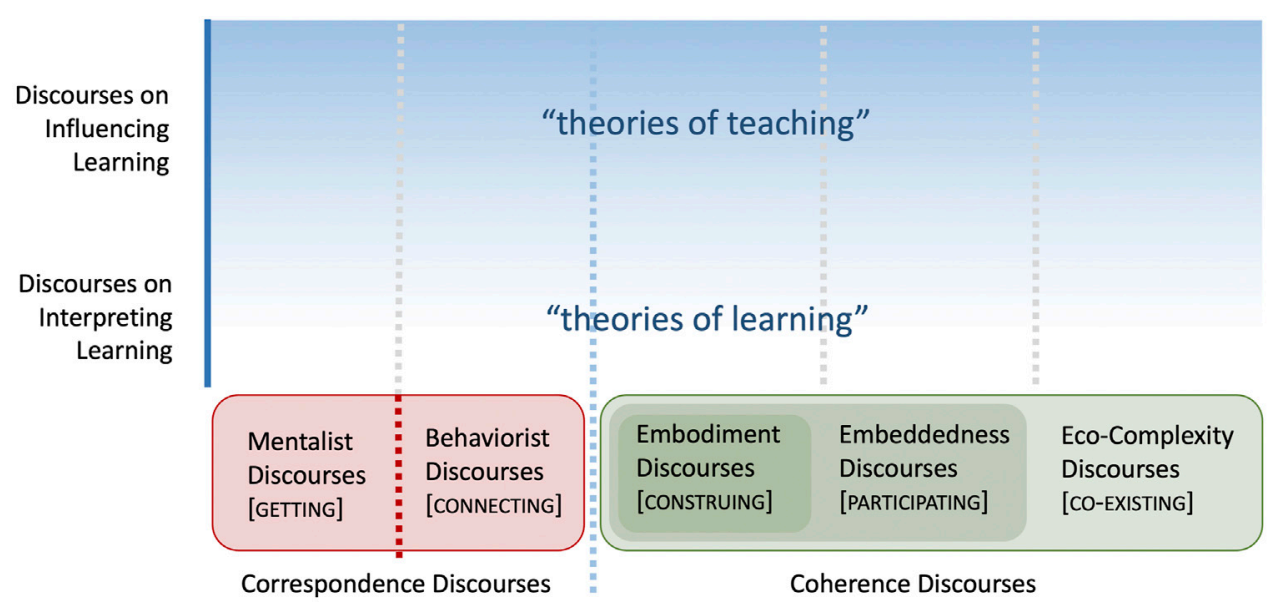

FIGURE 2 | The ten "regions" formed by our principal axes.

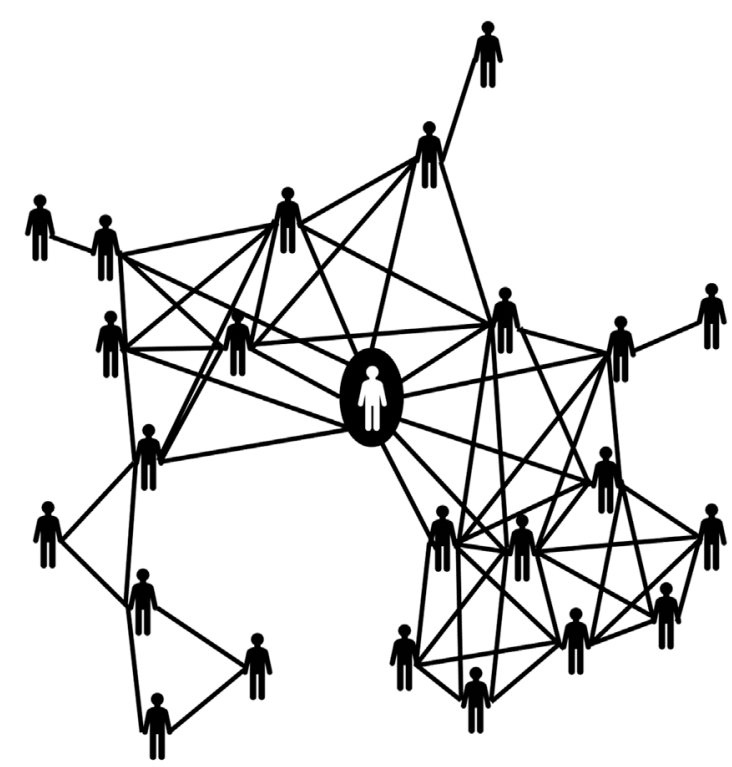

FIGURE 3 | A node-and-link diagram of a simple social network.

Our principal strategy for signaling these sorts of relationships is the identification of "clusters" that highlight common features. These are represented on the map as overlapping ellipses. The result bears a resemblance to a Venn diagram, but it should not be interpreted as such. Unlike the information represented in setbased, logic-driven Venn diagrams, our clusters reflect broad and porous themes rather than logically defined and clear-cut qualities.

This cluster-based strategy reflects a significant departure from an initial intention in the project. Originally, we aimed to conduct a different type of network analysis that, like most, was to be focused on identifying links among nodes in a system. A simplified illustration is provided in Figure 3, in which we have drawn social connections between individuals in a social network.

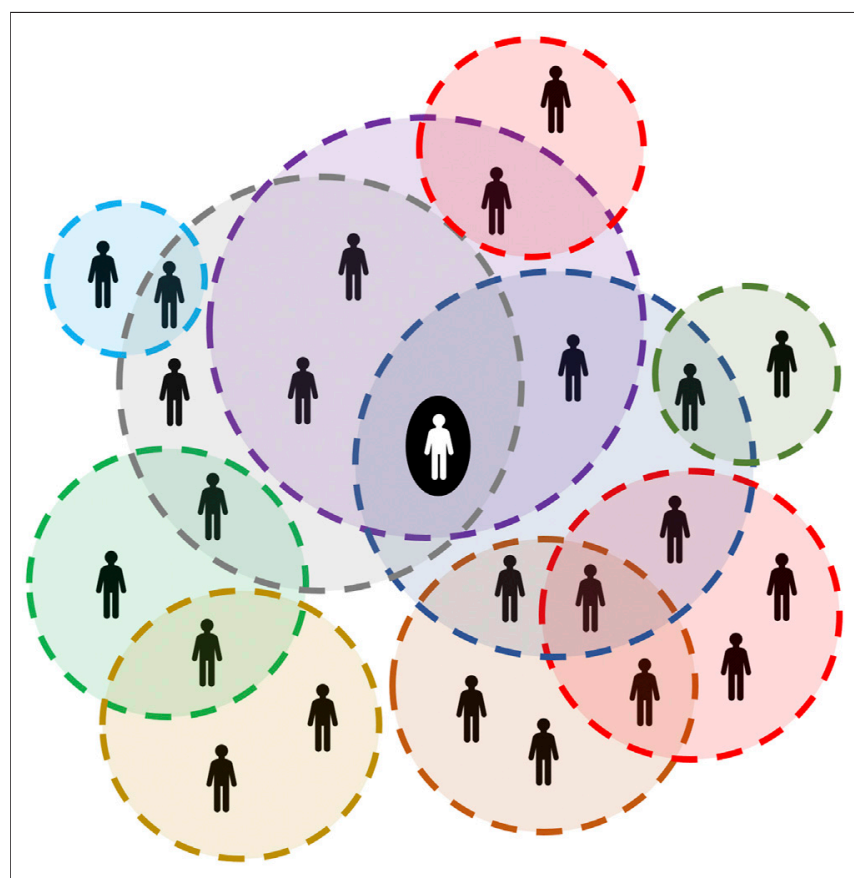

FIGURE 4 | A cluster-based diagram of a simple social network.

It is usually easy to trace chains of association of these node-andlink graphs, and so they can be not just useful, but intuitive for making sense of proximity and distance among agents (e.g., Goodreau et al., 2020). However, these diagrams are not without their limitations, and we found ourselves grappling with two intertwining issues as we attempted our plots. Firstly, because we touch on multiple dimensions of association in our analyses-such as focus, grounding metaphors, grain-size, and relative emphasis on teaching-our first attempt at a node-and-link graph quickly began to resemble a hairball. Secondly, taming the hairball and rendering the graph more readable entailed culling categories of association, thus muting vital information on relationships. 
TABLE 1 | Clusters used to highlight associations among learning discourses.

a posteriori Discourses

a priori Discourses

Activist Discourses

Activity- and Experience-Focused Discourses

Association-Making Strategies

Brain-as-Computer Discourses

Collectivist Learning Theories

Consequential Educational Practices

Cybernetic-Systems Discourses

Developmental Discourses

Directive Pedagogies

Discourses on Individual Learning in Group Settings
Discourses on Learning Collectives

Ecological Discourses

Emergent Complexity Discourses

Emergent Design Discourses

Epistemology

Extrinsic Motivation Discourses

Folk Theories

Identity Discourses

Intrinsic Motivation Discourses

Language-Focused Discourses

Learner Trait Discourses

Learning-Machine Discourses
Motivation Theories

Mysticism- and Religion-Aligned Discourses

Neuro-Focused Discourses

Non-Trivial Constructivisms

Personal Agency Discourses

Postcognitivist Discourses

Psyche-Focused Discourses

Socio-Cultural-Focused Discourses

Technology-Mediated Individual Learning

Ubiquitous Metaphors of Learning

Unaffiliated Discourses

Well-Being Discourses
Unable to balance the competing impulses to simplify and to retain information, we abandoned the node-and-link approach and opted for a feature-based clustering strategy, as illustrated in Figure 4, which includes all the linking information in Figure 3, in the form of clusters laid atop precisely the same set of nodes. While less amenable to quantitative analysis than node-and-link representations, this sort of cluster-based diagram affords more immediate detail on "familial" relationships.

At the time of this writing, our map has 36 clusters (see Table 1). Some discourses occupy just one bubble, but most occupy several. Positive Psychology, for example, sits inside four bubbles: Identity Discourses, Well-Being Discourses, Intrinsic Motivation Discourses, and Psyche-Focused Discourses. As this example illustrates, intersections of clusters provide considerable information on a discourse's foci, metaphors, and associations.

Clusters arose organically. Typically, as sufficient numbers of entries were plotted according to our axes, "families" of discourses began to be noticeable-landing in relative proximity owing to common metaphors, shared foci, and so on. Indeed, the process of identifying clusters of discourses occasionally served as a sort of verification or validityaffording exercise for us. To illustrate with our most recent cluster, the demarcation of "Well-Being Discourses" was a simple matter of laying on an ellipse after a colleague observed that her theoretical interests (around well-being) were represented on the map, but not yet labeled.

\section{Additional Strategies to Compare, Contrast, and Connect}

We use three more strategies to highlight convergences and divergences among discourses. The first of these was designed to address the fact that many entries, such as Learning Styles Theories, Self-Directed Learning, and Psychotherapies, have literally dozens of associated discourses-that is, subdiscourses that share the same roots and metaphors, but that vary modestly according to focus, strategy, subclassifications, or some other emphasis. In such cases, rather than further cluttering the map, we included annotated lists of subdiscourses inside the parent entries.

A second integrative strategy involves highlighting prominent and representative metaphors for learning, learners, teaching, and education, laid out in bands that stretch across the map. Of course, these brief lists in no way capture the full ranges of interpretation present across even subregions, but they are useful for highlighting broad themes and as reminders that ideas fly in flocks.

Our third strategy is the use of color-coding to indicate the scientific status of each discourse: RED labels for discourses that lack coherent empirical support, AMBER for discourses that have limited or contested empirical support, and GREEN for discourses with substantial and consistent empirical groundings.

Pending sufficient resources and access to expertise to enable implementation, we are in the process of developing other strategies to incorporate more information into the map. One of these strategies involves a third, temporal dimension, which we imagine might work by "spinning" the current interface to view where entries fall along a timeline. Our initial pen-and-paper renderings of this information reveal clear time-indexed trends and branching patterns that, as might be expected, bear strong resemblances to phylogenetic (evolutionary) trees.

Another potential strategy involves developing a means to indicate the relative popularity of each discourse-through means, for example, analogous to cartographers' schemes for distinguishing among city populations. So far, we have resisted the temptation to do this, mainly because our focus is on ranges of thinking, not popularity of perspectives. In particular, we do not wish inadvertently to emphasize popular discourses with limited evidence (e.g., Learning Styles Theories; see Willingham, Hughes, \& Dobolyi, 2015) while de-emphasizing some rarely invoked discourses with robust empirical support. A second reason for not incorporating this strategy is that, as detailed in our opening, many different phenomena are collected under the word "discourses." As interesting as it might be to know, it is not apparent to us how we might determine the relative popularities of, say, Piaget's Genetic Epistemology and the Construction Metaphor.

Nevertheless, we suspect a map that provides some indication of relative popularity would be provocative. For the purpose of readability, the current map is drawn so that discourses are homogeneously distributed. That pragmatic feature might give the impression that Coherence Discourses dominate the field. However, if indications of popularity were layered in, the opposite impression would be projected. Developing the analogy that "popularity is like population," most of the metropolises on 
our map sit in the Correspondence Discourses region, and a large portion of the settlements in the Coherence Discourses region are just towns, villages, and perhaps even family farms.

Finally, we are keenly aware that, with few exceptions, the discourses on our map were authored in English. For those that were developed in other languages, we relied on English translations. Aware that the ecosystems of association of other languages are likely to support dramatically different sensibilities, it would seem reasonable to suspect that our map is a flawed representation of just a small province in a vast land. Prompted by this issue, we have started work on a project we hope might afford some access to discourses that may not be translated (or translatable) to English: We are engaging with educational researchers, whose native tongues are other than English, to identify principal metaphors for learning and associated flocks of association in their first languages. ${ }^{4}$ Although still early in the project, we can report that metaphors have emerged that are not represented in any of the discourses on learning that we have reviewed in English.

\section{PHASE 3: LEARNINGS FROM EXTENDING THE DATABASE \\ Some Theories of Learning are Little More than Elaborated Metaphors}

By the time we had finished plotting the entries from our preliminary database of discourses, we had realized that the map was evolving beyond a device to catalog and contrast discourses on learning into an investigative tool that is useful for seeking, identifying, and analyzing some of the fault lines of educational discourse.

In that regard, the first phases of the project had underscored that, within education, relatively few "theories of learning" are actually scientific discourses aimed at understanding the phenomenon of learning. Much to the contrary, in fact, there is a marked tendency to elevate common-sense beliefs and popular metaphors into "theories" by framing them in more academic-sounding ways. Two illustrative instances are the metaphors LEARNING As CONSTRUCTING and LEARNing as InPUTting. Addressing the former was straightforward, owing to incisive scholarship on the trivialization of 20th-century Constructivisms (e.g., von Glasersfeld, 1990). We deal with the matter on the site by contrasting popular uses of the Construction Metaphor with a cluster of Non-Trivial Constructivisms.

The LEARNING-AS-INPUTTING metaphor is another matter. This notion is part of a flock of associations that is popular both inside and outside the research community. That flock includes, for example, BRAIN AS COMPUTER, KNOWLEDGE AS INFORMATION, MEMORY AS STORAGE, and COGNITION AS PROCESSING, and its prominent members include Cognitivism, Information Processing Theory, Self-Regulated

${ }^{4}$ The emerging results of this companion project can be accessed at https:// learningmetaphors.com.
Learning, Learning Styles Theories, and Differentiated Instruction. That is, the LEARNING-AS-INPUTTING metaphor turns out to be foundational to academic theories and professional discourses that vary dramatically in focus and reputation. It would be reductionist and irresponsible to sweep all associated discourses aside with the charge of an indefensible grounding metaphor. Rather, the LEARNING-ASINPUTTING metaphor reminds that the issue with metaphoric associations is not rightness or wrongness. That is, according to Conceptual Metaphor Theory, the "truth" of a metaphor has more to do with utility for practitioners than fidelity to the phenomenon.

\section{Very Different Theories Sometimes use Very Similar Vocabularies}

Further to the matter, and specific to the BRAIN-AS-COMPUTER metaphor, it was interesting and disconcerting to us to learn that Brain-Based Learning, a popular discourse that embraces the metaphor BRAIN AS COMPUTER, claims the same conceptual territory as Neuroeducation, which is rooted in Neuroscience. The two discourses are incompatible. Indeed, proponents of Neuroeducation have been vocal in their condemnations of Brain-Based Learning (e.g., Jensen, 2000), citing it as a commercial interest that perpetuates neuromyths and peddles simplistic remedies to complex problems. Such discourses seem to gain traction not because they are tapped into science, but because they exploit familiar metaphors-highlighting that the larger issue here is that similar terms are often used to label incompatible sensibilities. Another example is the pairing of Embodied Learning and Embodied Cognition. The former is popular, but ill-defined and most often associated with an emphasis on physical engagement. The latter is rooted in Cognitive Science and specifically concerned with what is knowable for human bodies within human social systems. Yet another example is Deep Learning, which is associated with at least three distinct discourses-namely, a counterpoint to Shallow Learning, a synonym for 21st-Century Learning, and a subdomain of Machine Learning.

Two notions are especially notable for their multiple appearances and diverse meanings. In Table 2, we've assembled a list of titles that invoke action or construction in one form or another. These discourses land all over the map, signalling wildly diverse meanings despite similar-sounding names-and pointing to a complex issue for the field. It is not hard to imagine a conversation in which participants engage earnestly and sincerely on topics of active learning or constructed meanings, and yet fail to recognize that one another's assumptions on learning and teaching are incompatible. We cannot help but suspect that such conversations are commonplace among teachers and researchers.

At least two sorts of serious communicative rupture can occur in such conversations. Indexed to our map, one category might be labeled "horizontal breaks." This sort is perhaps best illustrated by the Activity- and Experience-Focused Discourses cluster, in which physical engagement and advice for teaching 
TABLE 2 | Two prominent notions among discourses on learning in education.

\begin{tabular}{|c|c|c|}
\hline Notion & action & construction \\
\hline Sample Entries & $\begin{array}{l}\text { Action Learning } \\
\text { Action Theory } \\
\text { Activate } \\
\text { Active Learning } \\
\text { Active Recall } \\
\text { Activity-Based Learning } \\
\text { Activist Discourses } \\
\text { Activity Systems Theory } \\
\text { Activity Theory } \\
\text { Activity-Dependent Plasticity } \\
\text { Actor-Network Theory } \\
\text { Cultural-Historical Activity Theory } \\
\text { Community of Action } \\
\text { Contextual Action Theory } \\
\text { Enactivism } \\
\text { Mediated Action } \\
\text { Mental Practice of Action } \\
\text { Social Action Theory } \\
\text { Theory of Reasoned Action }\end{array}$ & $\begin{array}{l}\text { Cognitive Constructivism } \\
\text { Collaborative Constructivism } \\
\text { Communal Constructivism } \\
\text { Construction Metaphor } \\
\text { Constructionism } \\
\text { Constructivist Gaming } \\
\text { Constructive-Developmental Theory } \\
\text { Critical Constructivism } \\
\text { Deconstruction } \\
\text { Expressive Constructivism } \\
\text { Human Constructivism } \\
\text { Neuroconstructivism } \\
\text { Personal Construct Theory } \\
\text { Piagetian Constructivism } \\
\text { Radical Constructivism } \\
\text { Reconstructivism } \\
\text { Relational Constructivism } \\
\text { Social Constructionism } \\
\text { Social Constructivism } \\
\text { Trivial Constructivism }\end{array}$ \\
\hline
\end{tabular}

are foregrounded. This cluster spans the full width of the map, meaning that underlying assumptions range from entrenched Folk Theories to cutting-edge research oriented by Ecological Discourses and Emergent Complexity Discourses. The other type of rupture might be called "vertical breaks." These are typically subtle, as they often invoke the same principles, but for different purposes. For example, Non-Trivial Constructivisms and Expressive Constructivism are aligned vertically. The latter is explicitly rooted in the former, but its narrow advice on encouraging articulation and dialogue is hardly reflective of the span of considerations of its source discourses.

\section{Discourses on Teaching Are Often Perched on Singular Principles of Learning}

Further to the previous point, there are many instances of discourses located in our upper region (i.e., concerned mainly with teaching) that claim to be aligned with discourses located in the lower region, but that do not reflect the sophistication of those source discourses. Indeed, it appears that a large portion of the discourses in the top half of our map can be appropriately described as efforts to translate one or a few cherry-picked principles of learning into broad prescriptions for teaching. For instance, in the 1990s, brain plasticity emerged in Neuroscience as a game-changing insight. In the decade that followed, that principle became foundational to popular discourses among educators, including Lifelong Learning (Fischer, 2000) and Mindset (Dweck, 2006).

Similarly, there are many ideology-infused discourses-which, operationally, we defined as perspectives that are principally articulated as imperatives for particular practices-such as group work, personal strategies, learner explanations, learner motivation tactics, and/or diagnostic testing-in absence of integrated theoretical treatments and empirical support.
Complex Instruction (Cohen, 1998) and Expansive Learning (Engeström, 2001) are two illustrations of this tendency. It is not difficult to trace the roots of these and other contemporary educational obsessions to specific principles of learning. However, in the absence of more nuanced awareness of the theories from which these bits of advice are drawn, and in ignorance of the sociopolitical influences behind the recommendations, it is quite another matter to invite critical considerations of why, when, and where the prescribed practices are fitting.

In this regard, based on use of the website in our own teaching, the map has proven useful as a device for tracing and interrogating the principles of learning that infuse advice for teaching. In the process, the site can be useful for highlighting issues and gaps that can arise when moving from (learning) theory and (teaching) practice. In the same vein, the site has proven useful for addressing desires to identify "best" teaching practices. When compelled to grapple with a spectrum of sensibilities, most of our students come quickly to the realization that discussions of "best" are pointless without making the ground of assumption more explicit-and, with that, engaging critically with matters of best where, when, and for whom.

\section{A Few Literalized Metaphors Pervade Virtually all Discourses on Learning}

In her analyses of the metaphors LEARNING AS ACQUISITION and LEARNING AS PARTICIPATION, Sfard (1998) exemplified some core tenets of Conceptual Metaphor Theory as she identified several vital qualities of metaphors. Perhaps most cogently, metaphors are most powerful when they operate implicitly. Unfortunately, the quality that renders metaphors potent tools of thought also renders them difficult to research, especially as these figurative devices come to be deployed as literal truths. And ironically, the 
more ubiquitous the metaphor of learning, the more difficult it is to recognize it, let alone critique it and consider alternatives. To explain, as mentioned above, an early decision in this project was to include prominent metaphors of learning alongside more formal theories. Our initial list of metaphors included ACQUISITION, ADAPTATION, CONNECTING, CONSTRUCTION, ILLUMINATION, INPUTTING, and PARTICIPATION. It was only well into the project that we realized that we failed to foreground the most common metaphors of learning in English, which we currently believe to be PATH-FOLLOWING and ASSOCIATION-MAKING.

The PATH-FOLLOWING metaphor is tied to the origins of the word "learn" in English, which is derived from the Proto-IndoEuropean root lois- "furrow" or "track." The metaphor is manifest in obsessions with learning goals, looking ahead, making progress, lesson trajectories, advanced understandings, slow learners, and guiding students, not to mention courses, discourses, and curricula (all of which derive from the Latin currere, "to run"). In the early stages of our analysis, we assumed that the pervasiveness of this metaphor had to do with history and cultural momentum. It was sobering to realize that the metaphor is foundational to discourses that are explicitly about challenging entrenched assumptions and practices-as is evident in the "progress" root of Progressivism, which was among the most impactful reformist discourses of the 20th century. Indeed, we have only encountered a handful of discourses on learning that do not rely on the PATH-FOLLOWING metaphor. Those few all sit in our Emergent Complexity Discourses cluster, where learning is interpreted more in terms of EXPANDING THE SPACE OF THE POSSIBLE. In every other cluster, the PATH-FOLLOWING metaphor is prominent, if not dominant. That detail is amplified in the top half of the map-as should be expected, given formal education's guiding image of paced progress toward well-defined ends.

Whereas the PATH-FOLLOWING metaphor is ubiquitous among discourses in the top, more teaching-focused portion of the map, the ASSOCIATION-MAKING metaphor is similarly ubiquitous among the discourses in the lower, more dynamics-focused portion. It is assumed across many discourses, as disparate as Empiricism, Representationalism, Behaviorisms, Radical Constructivism, Connectionism, and Psychoanalytic Theories-to mention just a few.

ASSOCIATION-MAKING is articulated in many ways. Prominent threads include 1) an assertion that human learning is mainly about making associations among experiences, 2) a supposition that activating a thought will likely activate associated thoughts, and 3) an acceptance that human cognition is largely non-logical. We encountered such principles routinely as the project unfolded. Yet, despite the frequent appearances of the word "association," we did not recognize it as a metaphor until well into the third phase of the work-underscoring for us both the power of implicit metaphors and the difficulty of researching them.

\section{It is Important to Consider Unfamiliar Metaphors}

Sinatra and Pintrich (2002) noted that some metaphors are more effective than others in enabling new thinking and prompting change. In that regard, less-familiar metaphors can typically be more disruptive. We will not dwell on this point, but we use it to explain the presence of some perhaps-unexpected entries on the map, especially in the lower right region. Admittedly, it is a stretch to assert that Plant Cognition, Animal Cognition, and Primate Cognition, along with the clusters Learning-Machine Discourses and Cybernetic-Systems Discourses, are "discourses on learning in education." At the same time, because many invoke and develop novel metaphors of learning, yet in ways that are compatible with other Coherence Discourses, we felt their inclusion might serve to interrupt and challenge.

\section{PHASE 4: LEARNINGS FROM USING THE MAP}

Another of our research commitments, Math Minds (2020), is a multiyear partnership involving university-based researchers, multiple school districts, and a not-for-profit resource developer. Currently in its ninth year, our collaboration is oriented by analyses of decades of research into the structures of mathematical concepts and the dynamics of human learning, and it is focused on the development of a theoretically defensible and evidence-based model of mathematics pedagogy.

While still evolving, our model has been shown to support robust and accelerated learning, with the most significant improvements in conceptual understanding and problem solving (Preciado-Babb et al., 2018; Davis and Metz, in press). Yet even with multiple years of evidence across multiple populations, we ran into an unexpected resistance when we set about to scale up the project a few years ago. As we reached out to other school districts, we met with criticisms from traditionalists and reformists alike, as each saw the work as lodged in the other's sensibilities.

To contextualize, school mathematics in North America has been immersed in "math wars" since the late 1980s. In coarse terms, the math wars draw a line between traditionalist (teachercentered, procedure-focused, outcomes-based approaches) and reformist (student-centered, understanding-focused, relevancebased emphases). In truth, we struggled to make sense of the situation when we first realized that both camps were critical of Math Minds. That changed when the learning discourses project began to take shape. In terms of map regions, as we illustrate in Figure 5, the arguments of traditionalists tend to rely on Correspondence Discourses, and the arguments of reformists tend to invoke Embodiment Discourses, especially those in the upper (Influencing Learning) region. The discourses that we draw on in Math Minds diverge from both. The work is informed by a swath of Coherence Discourses, most in the lower (Interpreting Learning) region extending into the Activist Discourses cluster (see Figure 5). That means, we suspect, our ways of talking about learning and teaching are unfamiliar to both our traditionalist and reformist critics. It may be that neither can hear their preferred metaphors echoed in our descriptions-and so, to each, we must be the other.

The situation continues to be frustrating, but the mapping project has afforded both reason for hope and conviction to 


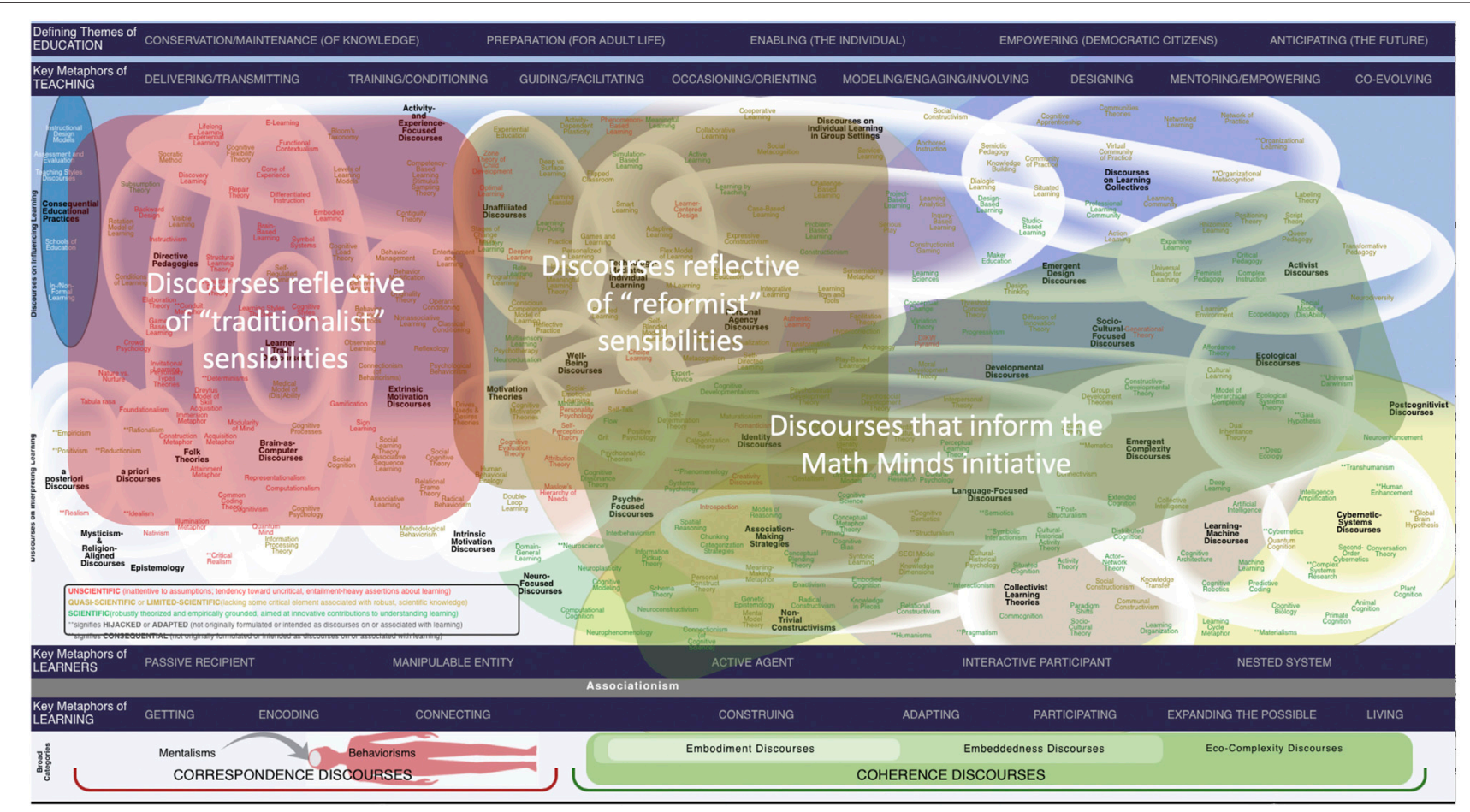

FIGURE $\mathbf{5}$ | Locating the two camps of the math wars and the Math Minds initiative.

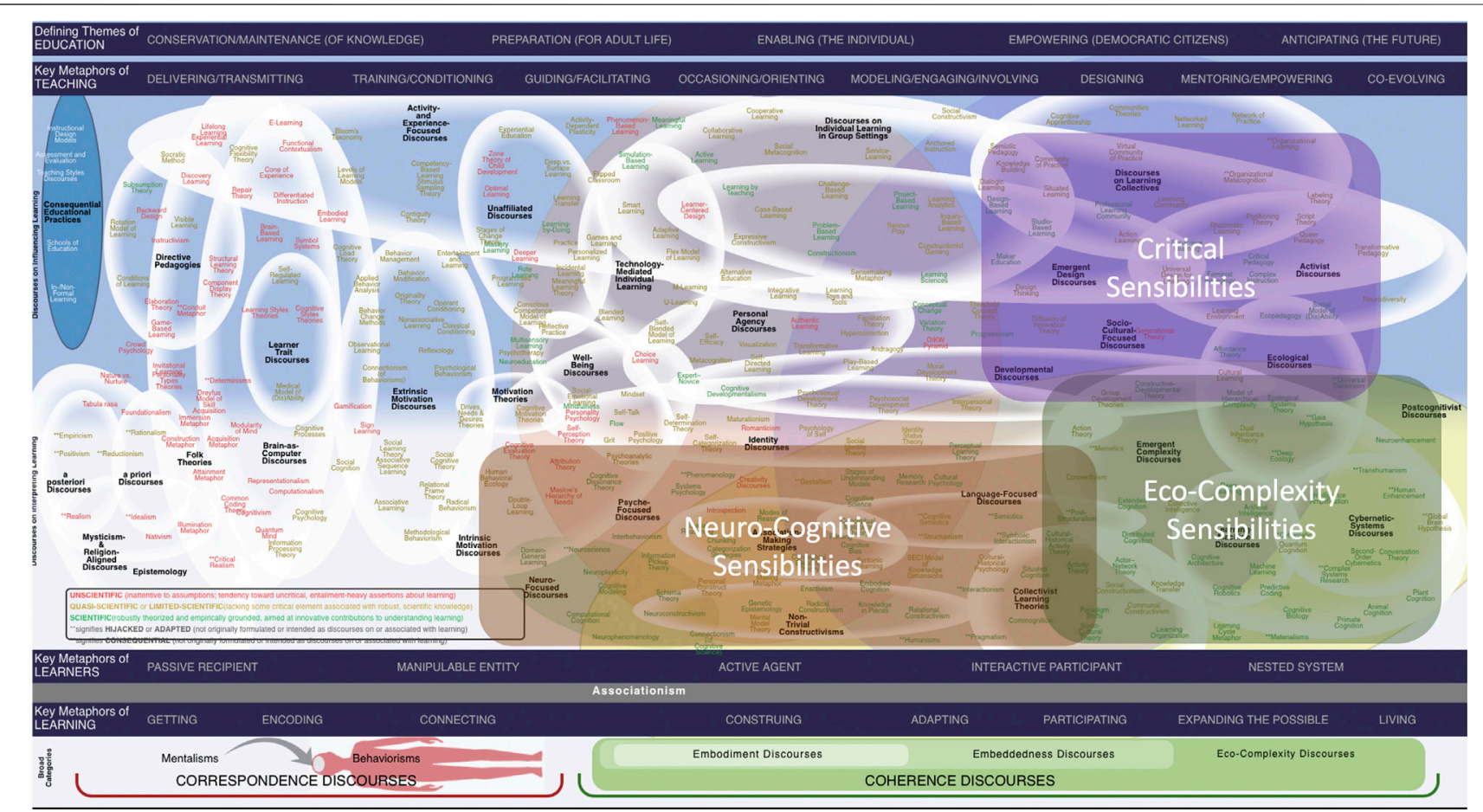

FIGURE 6 | Complementary, but not-necessarily-collaborating, specializations in education. 
persist. It has also helped us to better appreciate that some educational movements that self-describe as progressive and aimed at educational reform may be militating against meaningful change-not owing to ill intention, but because they are guilty of the same inward-looking, self-assured, and insulating tendencies as the sensibility they challenge.

We must implicate our own work here. While we imagine ourselves to be open-minded and broadly informed, the fact of the matter is we had no difficulty locating ourselves on Figure 5-that is, clearly distinguishing ourselves from both traditionalist and reformist sensibilities. We too have encamped, and that differentiated positioning is no doubt apparent in our habits of expression. Not without irony, those habits have emerged in ongoing efforts to work across at least three well-defined regions-namely, neuro-cognitive, critical, and eco-complexity sensibilities (see Figure 6).

To be clear, we are in no way critical of the impulse to specialize; rather, we are mindful of tendencies toward echo chambers that might inadvertently dampen other voices. Such tendencies are to be expected-as, in fact, is suggested by several entries in the Embeddedness Discourses region, including Cognitive Bias and Situated Cognition. Even so, in a domain as necessarily transdisciplinary as education, there would seem to be an obligation to subvert a penchant to silo. If the discourses just mentioned are taken seriously, such subversion entails deliberate and sustained effort.

In this regard, we think our mapping does more than place an exclamation point on the common acknowledgment that formal education is a conflicted enterprise that spans multiple concerns, addresses many issues, and is made to serve sometimesconflicting purposes. The analysis affords insight into why some debates cannot be resolved, and how others might be operating in ignorance of broad knowledges of learning and teaching. With that point in mind, the map is not just an account of "where things are"; it might also serve as a scan of possible horizons. In this regard, we re-emphasize the subtle pervasiveness of PATH-FOLLOWING and ASSOCIATION-MAKING metaphors of learning across popular and academic discussions of formal education, and we contrast that with

\section{REFERENCES}

Cobb, P. (1994). Where Is the Mind? Constructivist and Sociocultural Perspectives on Mathematical Development. Educ. Res. 23 (7), 13-20. doi:10.3102/ 0013189x023007013

Cohen, E. G. (1998). Complex Instruction. Eur. J. Intercultural Stud. 9 (2), 127-131. doi:10.1080/0952391980090202

Davis, B. (2004). Inventions of Teaching: A Genealogy. Mahwah, NJ: Lawrence Erlbaum.

Davis, B., and Metz, M. Metaphor and Learning Mathematics. For the Learning of Mathematics. (in press).

Davis, B. (2018). On the many Metaphors of Learning ... and Their Associated Educational Frames and Their Associated Educational Frames. J. Curriculum Stud. 50 (2), 182-203. doi:10.1080/00220272.2017.1330423

Davis, B., and Sumara, D. (2003b). A REPLY Listening to How You're Heard: On Translations, Mistranslations, and Really Bad Mistranslations. Teach. Edu. 14 (2), 149-152. doi:10.1080/1047621032000092940

Davis, B., and Sumara, D. (2003a). Why Aren't They Getting This? Working through the Regressive Myths of Constructivist Pedagogy. Teach. Edu. 14 (2), 123-140. doi:10.1080/1047621032000092922 emergent perspectives on learning in the Eco-Complexity Discourses region that do not rely on those metaphors. Those and other potentially disruptive perspectives should perhaps be drawing more attention from teachers, administrators, policy makers, and researchers.

We thus close where we began, with the observation that there is an evident need for educators and researchers to be more explicit and systematic in discussions of learning. Critically, our conviction is that these ideals should not be construed as a need for greater emphasis on empirical research. Indeed, to our analysis, even evidently scientific discourses on learning are riddled with unexplicated, often naïve, and occasionally problematic metaphors. That is, the greater need at present may be nuanced, transdisciplinary interpretive work that is informed by expertise with matters identified across the map. Among the many examples we could cite, we offer that Conceptual Metaphor Theory (Lakoff \& Johnson, 1999) and Enactivism (Varela, Thompson, \& Rosch, 1991) might serve as exemplars in this regard, particularly in the ways that their proponents have been critically attentive to grounding metaphors, orienting assumptions, pragmatic entailments, empirical evidence, and alignments with other discourses. The evolution of new horizons of educational possibility might be better served by efforts to understand the current discursive landscape than by claiming and defending patches of that terrain.

\section{DATA AVAILABILITY STATEMENT}

The datasets presented in this study can be found online at https://learningdiscourses.com.

\section{AUTHOR CONTRIBUTIONS}

All authors listed have made a substantial, direct, and intellectual contribution to the work and approved it for publication.

Dweck, C. S. (2006). Mindset: The New Psychology of success. New York: Random House.

Engeström, Y. (2001). Expansive Learning at Work: Toward an Activity Theoretical Reconceptualization. J. Edu. Work 14 (1), 133-156. doi:10.1080/ 13639080020028747

Fauconnier, G., and Turner, M. (2003). The Way We Think: Conceptual Blending and the Mind's Hidden Complexities. NY, US: Basic Books.

Fischer, G. (2000). Lifelong Learning: More Than Training. J. Interactive Learn. Res. 11 (3/4), 265-294.

Goodreau, S. M., Pollock, E. D., Birnbaum, J. K., Hamilton, D. T., and Morris, M. (2020). Can't I Please Just Visit One Friend?: Visualizing Social Distancing Networks in the Era of COVID-19. Available at: http://statnet.org/COVID-JustOneFriend/.

Jensen, E. (2000). Brain-Based Learning: A Reality Check. Educ. Leadersh. 57 (7), 76-80.

Kelly, K. (2010). What Technology Wants. NY, US: Penguin.

Lakoff, G., and Johnson, M. (1999). Philosophy in the Flesh. NY, US: Basic Books. Macdonell, D. (1986). Theories of Discourse: An Introduction. NY, US: Wiley.

Marton, F., and Säljö, R. (1976). On Qualitative Differences in Learning: I-Outcome and Process*. Br. J. Educ. Psychol. 46 (1), 4-11. doi:10.1111/ j.2044-8279.1976.tb02980.x 
Math Minds (2020). Math Minds. Available at: https://www. structuringinquiry.com.

Preciado-Babb, P., Metz, M., Sabbaghan, S., and Davis, B. (2018). "The Role of Continuous Assessment and Effective Teacher Response in Engaging All Students," in Mathematics Discourses that Breaks Barriers and Creates Space for Marginalized Learners. Editors R. Hunter, M. Civil, B. Herbel-Eisenmann, N. Planas, and D. Wagner (Rotterdam, N: Sense), 101-120.

Seel, N. M. (Editor) (2012). Encyclopedia of the Sciences of Learning (Cham, CH: Springer).

Sfard, A. (2015). "Learning, Commognition, and Mathematics," in The Sage Handbook of Learning. Editors D. Scott and E. Hargreaves (London: Sage), 129-138.

Sfard, A. (1998). On Two Metaphors for Learning and the Dangers of Choosing Just One. Educ. Res. 27 (2), 4-13. doi:10.3102/0013189x027002004

Sinatra, G., and Pintrich, P. (Editors) (2002). Intentional Conceptual Change (Mahwah, NJ: Lawrence Erlbaum Associates).

Thibodeau, P. H., and Boroditsky, L. (2015). Measuring Effects of Metaphor in a Dynamic Opinion Landscape. PLoS ONE 10 (7), e0133939. doi:10.1371/ journal.pone.0133939

Thibodeau, P. H., and Boroditsky, L. (2013). Natural Language Metaphors Covertly Influence Reasoning. PLoS ONE 8 (1), e52961. doi:10.1371/journal.pone.0052961

Varela, F., Thompson, E., and Rosch, E. (1991). The Embodied Mind: Cognitive Science and Human Experience. Cambridge, MA: The MIT Press. von Glasersfeld, E. (1990). An Exposition of Constructivism: Why Some like it Radical, Monogr. J. Res. Maths. Edu. 4, 19-29. doi:10.2307/749910

Willingham, D. T., Hughes, E. M., and Dobolyi, D. G. (2015). The Scientific Status of Learning Styles Theories. Teach. Psychol. 42 (3), 266-271. doi:10.1177/ 0098628315589505

Conflict of Interest: The authors declare that the research was conducted in the absence of any commercial or financial relationships that could be construed as a potential conflict of interest.

Publisher's Note: All claims expressed in this article are solely those of the authors and do not necessarily represent those of their affiliated organizations, or those of the publisher, the editors and the reviewers. Any product that may be evaluated in this article, or claim that may be made by its manufacturer, is not guaranteed or endorsed by the publisher.

Copyright (c) 2021 Davis and Francis. This is an open-access article distributed under the terms of the Creative Commons Attribution License (CC BY). The use, distribution or reproduction in other forums is permitted, provided the original author(s) and the copyright owner(s) are credited and that the original publication in this journal is cited, in accordance with accepted academic practice. No use, distribution or reproduction is permitted which does not comply with these terms. 